\title{
Epistemología de la historia ambiental a través de una encuesta realizada en el VII Simposio de la Sociedad Latinoamericana y Caribeña de Historia Ambiental (2014)
}

DOI: $10.5935 / 2237-2717.20150006$

\section{Epistemology of environmental history through a survey in the Seventh Symposium of the Latin American and Caribbean Society of Environmental History (2014)}

\author{
Gerardo Morales Jasso \\ Universidad de Guanajuato \\ gerardosansa@gmail.com \\ Guanajuato \\ Mexico \\ Jessica Herrera Montelongo \\ Mexico
}

Recibido: 15 de juño de 2015

Aprobado: 27 de agosto de 2015

\section{RESUMEN}

Este artículo busca destacar algunas tensiones que subyacen en la historia ambiental mediante abordar: 1) Las definiciones de ambiente que más aceptan los historiadores ambientales y sus implicaciones epistemológicas 2) La ubicación de la historia ambiental para con las ciencias sociales, las ciencias naturales y las humanidades 3) La relación de la historia ambiental para con la historia social 4) La caracterización de la historia ambiental como transdisciplina, interdisciplina 0 disciplina. En el artículo se desarrollarán tāles discusiones a través del análisis de las respuestas a una encuesta realizadas en el marco del VII Simposio SOLCHA que se realizó en Quilmes, Argentina. Además de comunicar los resultados de la encuesta, su análisis permitirá 1) plantear algunos presupuestos epistemológicos envueltos en las respuestas de los encuestados, 2) aumentar la reflexividad de la historia ambiental, 3) ayudar a distinguir los sentidos de to ambiental, I0 medioambiental y lo socioambiental.

\section{PalaVRas-chaVe}

Epistemología, historia ambiental, SOLCHA.

\begin{abstract}
This article seeks to highlight some tensions that underlie toward environmental history: 1) The most accepted definitions of environment by environmental historians and their epistemological implications. 2) The location of the environmental history of the social science, natural sciences and humanities. 3) The relationship of environmental history with respect to social history. 4) The characterization of environmental history as transdiscipline, interdiscipline or discipline. In the article such discussions will be developed such discussions through the analysis of responses to a survey carried out under the Seventh Symposium SOLCHA held in Quilmes, Argentina. In addition to communicate the survey's results, the analysis will 1) raise some epistemological assumptions involved in survey responses, 2) increase the self-reflexivity of environmental history, and 3) help distinguish the senses of environmental, milieu-environmental and socio-environmental.
\end{abstract}

\section{KEYWORDS}

Epistemology, environmental history, SOLCHA. 


\section{Introducción}

En, este texto se sigue la premisa de Heinz von Foerster de que "tenemos que observar nuestra propia observación y, en última instancia, dar cuenta de nuestro propio dar cuenta", lo que nos puede hacer capaces de "dar cuenta de [nuestra] propia epistemología". 1 Esto implica que realiza una aproximación a la historia ambiental mediante la epistemología de segundo orden. Es decir, busca observar no a lo observado, como se hace en la epistemología de primer orden; sino que intenta observar al observador. La observación del observador es una tarea parcialmente realizada por la historia de la historia, comúnmente llamada historiografía, pero como historia tiene el doble significado de res gestae y de rerum gestarum, en este texto historia significará res gestae e historiografía significàrá rerum gestarum. Sin embargo, lo que aquí se analiza no son publicaciones, sino que analizan las respuestas que dieron diversos historiadores ambientales a preguntas de naturaleza teórica sobre la misma con el fin de que se reflexione y debata sobre éstas. Tal entrevista se realizó en español, de modo que algunas palabras serán colocadas entre corchetes en el idioma original en que respondió el encuestado. Es también necesario aclarar que mientras que en la tradición anglosajona la historia pertenece a las humanidades, en otros idiomas la historia tiene herencias por parte de las ciencias sociales y de las humanidades.

El objetivo de plasmar los resultados de tal encuesta es revelar una tensión existente entre historiadores ambientales, mediante lo que habría de comprobarse a través de otras investigaciones, sería un cambio de pauta.2 Como menciona Gastón Bachelard, "La esencia misma de la reflexión es comprender que no se había comprendido."3

\section{Metodología}

Este trabajo muestra los resultados de una encuesta realizada en el marco del VII Simposio de la Sociedad Latinoamericana y Caribeña de Historia Ambiental, realizada el 2014 en Quilmes, Argentina. Los autores de este artículo entregaron encuestas por escrito a los asistentes. De todas las copias entregadas a estos, Ios autores sólo se recibieron 39. A este número se suma una encuesta respondida de un académico cuya ponencia fue aceptada, pero no pudo asistir, de modo que el total de encuestas respondidas asciende a 40 . Con el fin de que se pudiera ubicar a los encuestados, pero que pudieran responder abiertamente, se les pidió que escribieran su nombre si así lo deseaban. Aunque el nombre era opcional, debían plasmar su formación 0 área de especialización, así como su grado terminado de estudios.

Además de los datos anteriores, la encuesta consistió en cuatro preguntas. La primera, la segunda y la cuarta tuvieron respuestas predeterminadas con posibilidad a que si el encuestado no estaba conforme con estas pudiera responder otra opción. La tercera fue una pregunta abierta. A todas las preguntas recibieron un análisis estadístico y uno epistemológico que no pretende ser uno de epistemología normativa, sino de epistemología descriptiva.

\section{Análisis cuantitativos y enumeración de respuestas}

De los encuestados, uno tenía postdoctorado, diecinueve encuestas fueron respondidas por académicos con el doctorado finalizado, respondieron once con grado de maestros y nueve con el grado de licenciados. Del total de encuestas, once carecen de nombres (siete de estas tuvieron un nivel de doctor, uno de maestro y tres de licenciado). Respecto a la especialidad, quince se caracterizaron como historiadores, seis como historiadores ambientales, tres como antropólogos, dos como geógrafos, dos como trabajadores sociales, dos como historiadores de la ciencia, dos como comunicadores, uno como arquitecto, otro como profesor, otro como

\footnotetext{
${ }^{1}$ Foerster, Heinz von. Las semillas de la cibernética. Obras escogidas. Edición de Marcelo Pakman. Presentación de Carlos Sluzki (Barcelona: Gedisa, 1991$)$, 92, 143.

2 Bateson, Gregory. Espíritu y naturaleza (Buenos Aires: Amorrortu, 2006), 64, 65.

${ }^{3}$ Bachelard, Gaston. El nuevo espíritu científico (México, Nueva Imagen, 1981), 153.
} 
psicólogo ambiental, òtro como científico natural, los demás plantearon diversas especialidades que bien pudieran ser realizadas desde la historia 0 desde otra disciplina.

Del total de encuestados 17 fueron hombres, 18 mujeres y como el análisis de las encuestas fue después de terminado el VII SOLCHA, no se pudo determinar esta variable en 5 de las encuestas realizadas.

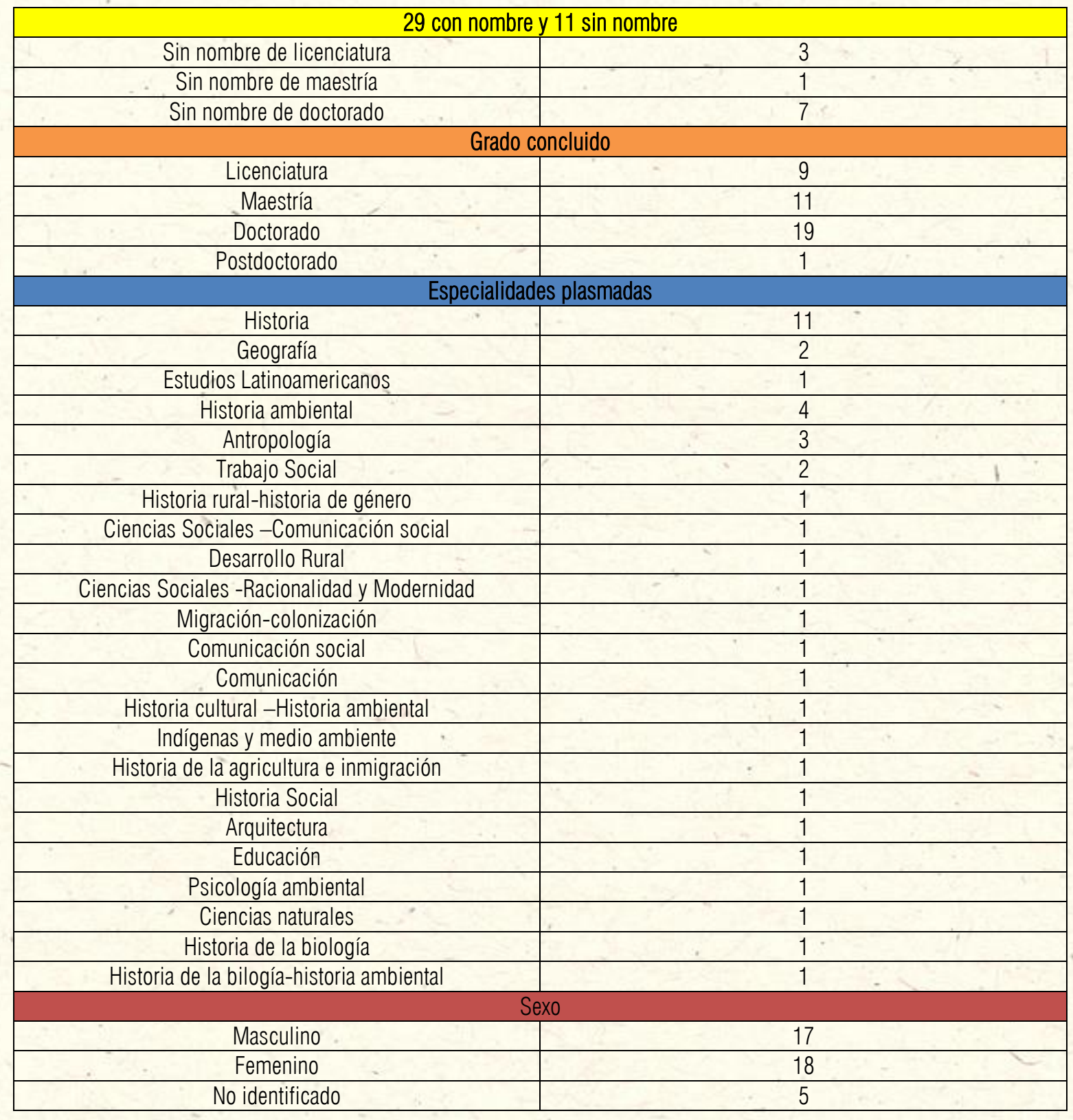

\section{Definición de ambiente}

La primera pregunta planteaba que el encuestado escogiera "la definición de Ambiente que más satisface el concepto que maneja". Las opciones fueron 1) El conjunto de características físicas, químicas y biológicas que tienen un lugar determinado. 2) Naturaleza socializada, es decir, naturaleza ya no tan natural, sino que domesticada; de cierto modo artificializada. 3) La articulación no dualista (sino compleja) entre sociedad y naturaleza. 4) Otra.

29 encuestados escogieron la opción tres, 7 escogieron la opción cuatro y 4 la respuesta dos. Uno de quienes escogieron la segunda opción añadió que "existen medios ambientes naturales y otros no tanto, estos segundos son los que tienen influencia de la acción del hombre". Otro de los que se decantaron por esta definición planteó que la primera y la segunda opción "pueden ser entendidas como sinónimos, porque las características 
físicas han sido alteradas por la gente a través de los años". Dos de quienes escogieron la tercera opción fueron María Cecilia Gallero y Jo Klanovicz, quienes complementaron tal definición: la primera indicó que a esta definición añadiría "el concepto de ecosistema (Gallini, 2005)", mientras que el segundo, citando a Lawrence Buell, entiende "ambiente como una síntesis de las dimensiones naturales y construidas del mundo palpable".

De quienes escogieron la cuarta opción, dos encuestados plantearon que la definición que manejan de ambiente está entre la segunda y la tercera definiciones planteadas, otro que implica las relaciones entre lo humano y lo no humano, de modo que "es una reflexión más desde los estudios sociales de la ciencia y la tecnología". Ely Bergo de Carvalho contestó que la definición que maneja de medio ambiente es la de "un lugar determinado y/o percibido donde están en relación dinámica y en constante interacción los aspectos naturales y sociales. Esas relaciones causan procesos de creación cultural y tecnológica y procesos históricos y políticos de transformaciones de la naturaleza y de la sociedad", es decir, la definición planteada por Marcos Reigota en 0 que é educaçao ambièntal. Otro escribió que el ambiente implica "las relaciones físicas, biológicas y culturales que se entretejen en el ir y venir de la vida", otro manifestó que es "la articulación no dualista entre sociedad y naturaleza", con lo que no aceptó la complejidad planteada en la opción tres, mientras que Patricia Clare modificó la primera opción para definir ambiente como el "complejo de características físicas, químicas y biológicas del que se compone un lugar determinado", con lo que estableció otra definición de transición entre la primera y la tercera, más cercana a la opción uno que la opción dos.

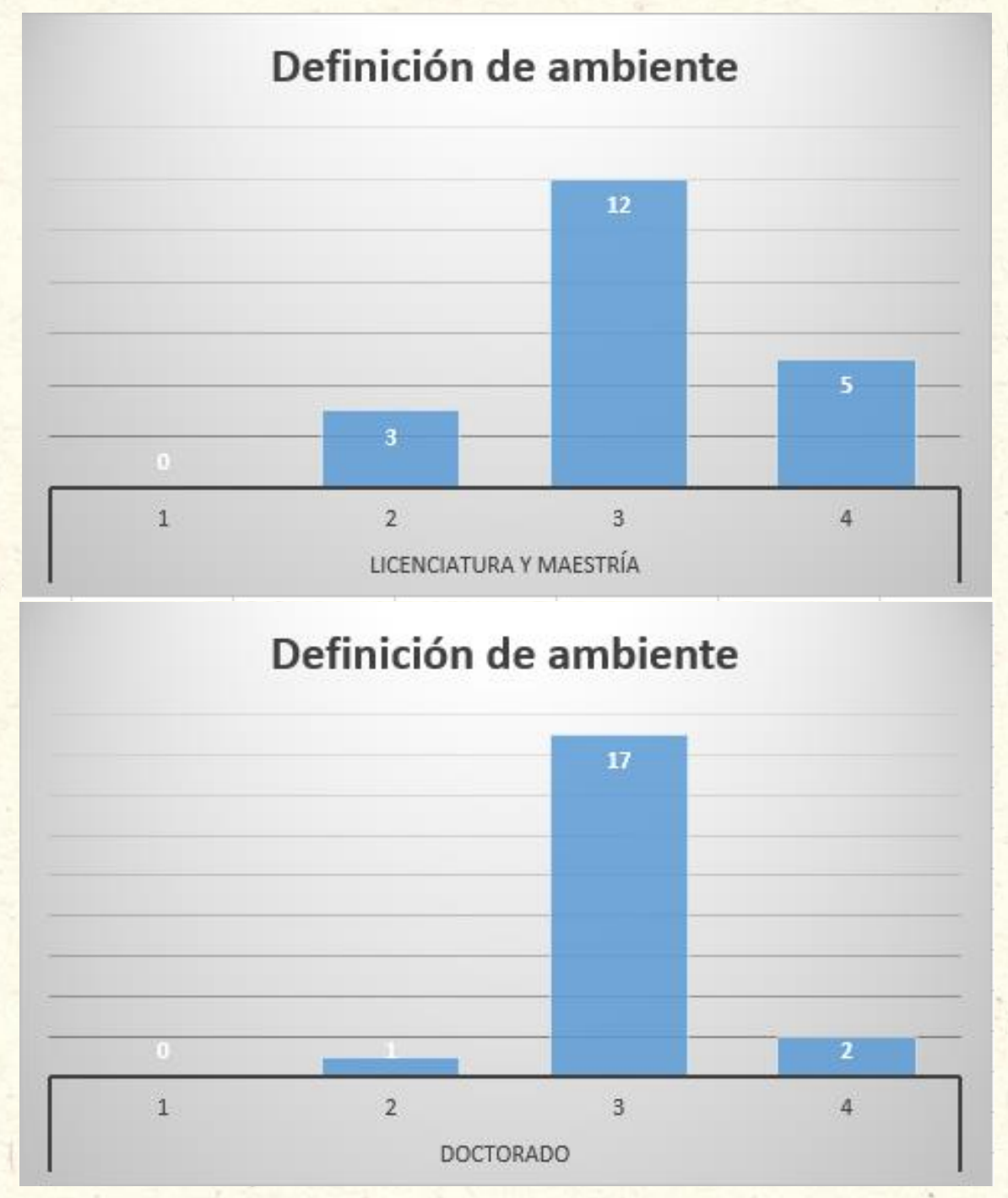




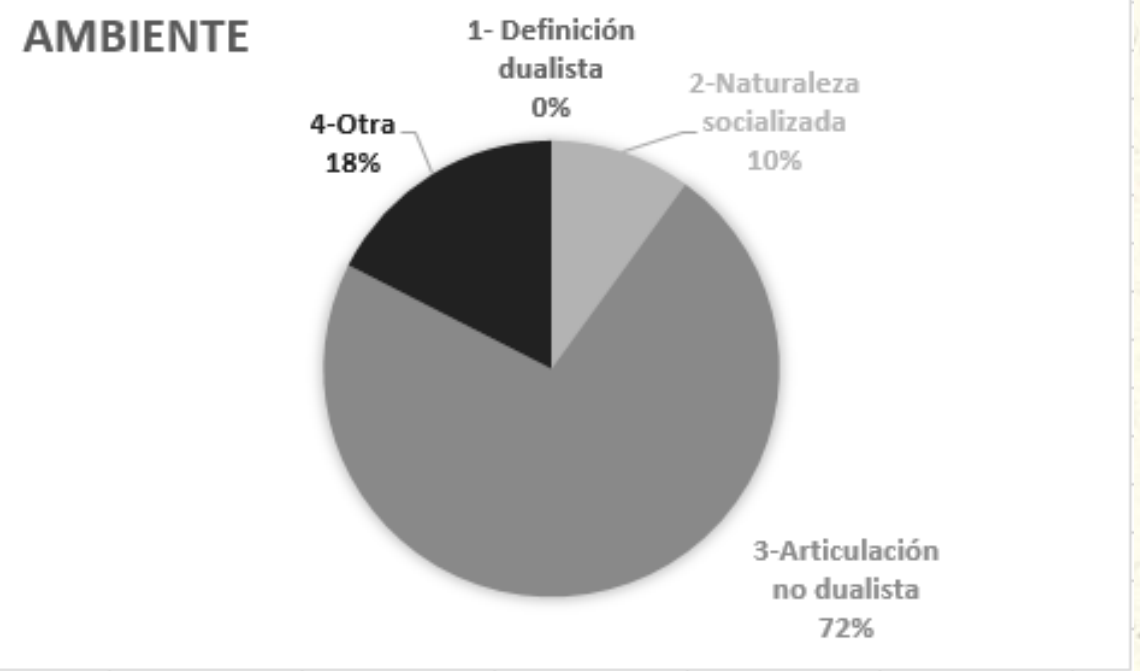

\section{¿A dónde pertenece la historia ambiental?}

En la segunda pregunta se buscó que el encuestado escogiera si ubica a la historia ambiental en 1) las humanidades, 2) las ciencias sociales, 3) las ciencias naturales, u 4) otro cuerpo de conocimientos, y que de ser posible justificara o extendiera su respuesta.

17 personas no pudieron ubicar a la historia ambiental únicamente en las tres áreas del saber predefinidas por la encuesta, 11 plantearon que la historia ambiental forma parte de las humanidades, 10 la ubicaron entre las ciencias sociales, sólo 1 la conciben como ciencias naturales. De modo que el 57\% de los encuestados pudieron ubicarla como perteneciente a una de las áreas del árbol del conocimiento tradicional.

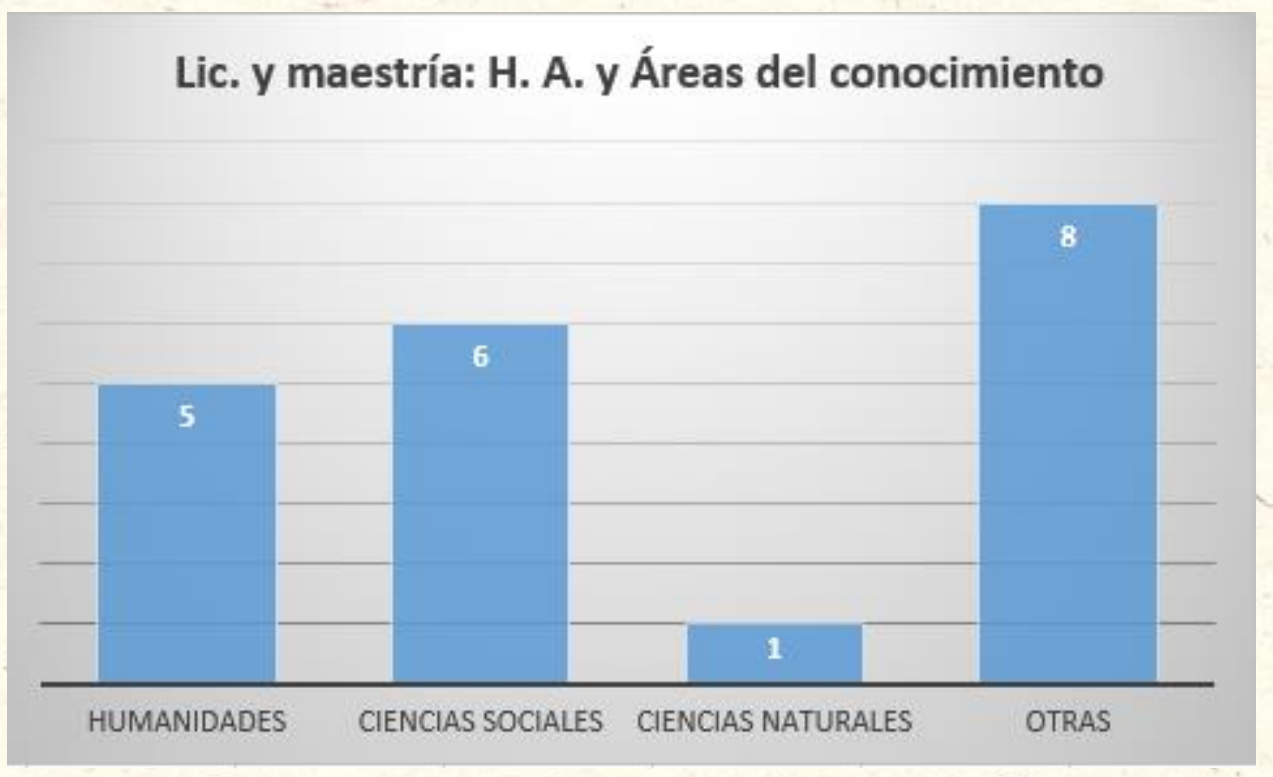

Algunos académicos explicaron que la.historia ambiental pertenece a las humanidades por ser híbrida, "porque trata las relaciones entre hombre y ambiente, siendo también un cuestión social", Jo Klanovicz planteó que porque "rearticula los colectivos de humanos y no humanos". Otro de los encuestados indicó que es parte de las humanidades "porque debe contemplar el aspecto social y relacionarlo con el entorno" y "porque la historia ambiental se remite al estudio de las formas de relacionamiento entre las diferentes culturas del pasado con la naturaleza en cuanto al uso que le han dado a sus recursos y ecosistemas devolviéndonos un espejo en el que las sociedades de hoy nos miramos".

Entre quienes plantearon que la historia ambiental forma parte de las ciencias sociales hubo quien mencionó que es porque en estas "se articulan complejamente las relaciones entre sociedad y naturaleza, bajo el 
prisma transdisciplinàr". Uno mencionó que "la compresión más satisfactoria de las cuestiones ambientales necesita de las herramientas interdisciplinarias que puedan propiciar otras ciencias sociales" además de la historia. Hubo quien destacó las transformaciones que el hombre ha realizado sobre el ambiente y su dominación, también hubo quien destacó el carácter relacional de la historia ambiental. Alguien más mencionó que la historia ambiental ha sido abordada por historiadores, sociólogos, antropólogos y que "la temática que relaciona ambiente y sociedad puede ser abordada por diferentes perspectivas". Katherinne Giselle Mora Pacheco mencionó que "para hacer historia ambiental se requiere de teorías y métodos propios de las ciencias sociales (análisis e interpretación de fuentes, trabajo con comunidades, historia oral, etc.) porque la sociedad es el asunto central". Uno de los encuestados destacó que es ciencia social [porque] la "historia se relaciona con [los] seres humanos". Gabriel Garnero contestó que "dejando de lado la discusión en torno a la validez de la división de la ciencia en aquellas categorías, creo que la mayoría de los trabajos de Historia Ambiental puede ubicarse dentro de las ciencias sociales. A p̀esar de poseer un enfoque que requiere de dialogo con conocimientos o aportes de las ciencias naturales, sigue teniendo un fuerte anclaje en la capacidad de ofrecer interpretaciones y construcciones teóricas que se enlazan a la tradición de las ciencias históricas. La temática ambiental es transversal, pero el aporte específico de la historia ambiental es ofrecer análisis diacrónicos sólidos".

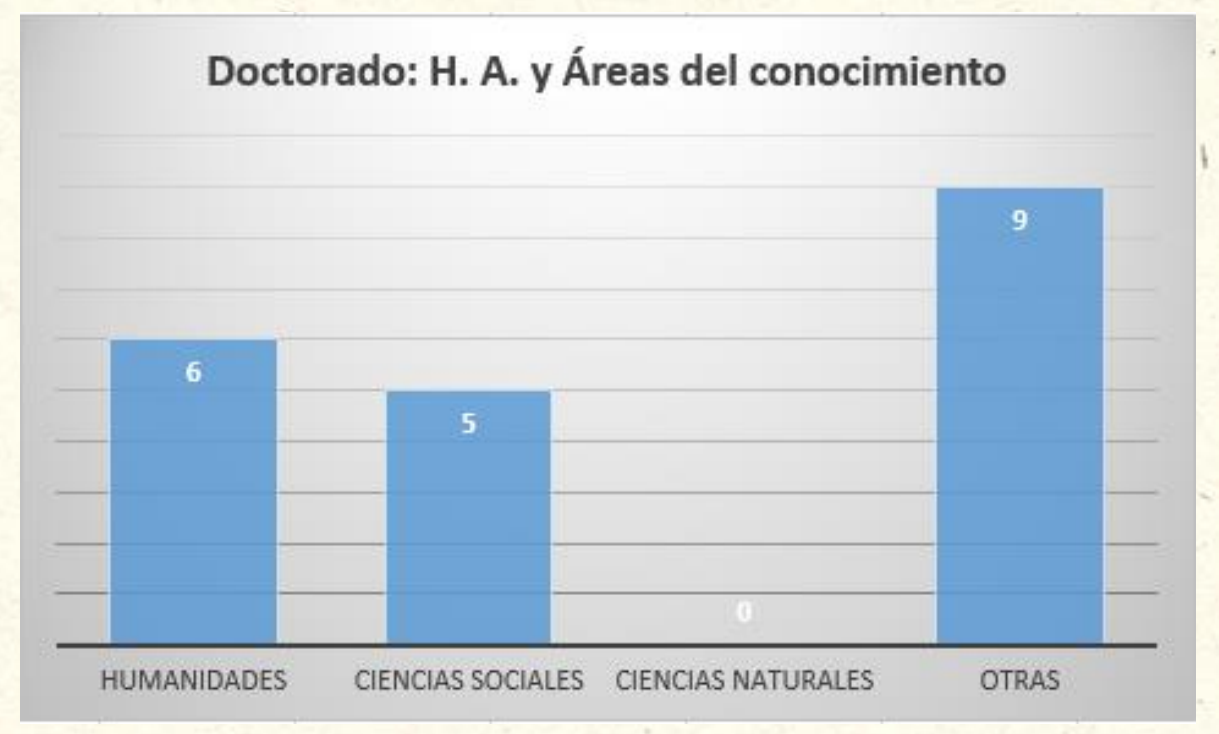

El único que planteó que forma parte de las ciencias naturales mencionó que si bien, "hay una enorme importancia de lo social", históricamente la historia ambiental "ha sido investigada desde las ciencias naturales".

Entre quienes no la ubicaron en alguna de las opciones anteriores, tres plantearon que la historia ambiental es transdisciplinar, de entre ellos, uno añadió que "en ese sentido y utilizando las categorías incluidas en esta pregunta ubicaría la historia ambiental en la intersección entre humanidades, ciencias sociales y ciencias naturales". De forma similar, seis de los encuestados plantearon que la historia ambiental se ubica tanto en las humanidades como en las ciencias sociales y naturales; alguien añadió que "porque todo tiene una historia", otro adujo que "porque la historia ambiental es un conjunto de acciones humanas sobre una formación física o natural". Uno de los encuestados destacó que la historia ambiental es una "disciplina compleja que debe incluir la relación ser humano-naturaleza". Dos plantearon que es un enfoque histórico interdisciplinar, uno de ellos añadió que "con aportes de otras áreas, inclusive las tecnológicas". Alguien planteó que "Ios-estudios de historia ambiental poseen una característica multidisciplinar, una vez que algunas cuestiones necesitan de diferentes miradas para ser comprendidas". Dos plantearon que es tanto ciencia social como ciencia natural, uno de quienes fue María Eugenia Solari quien planteó que "debe ser un campo inter-transdisciplinario que una ciencias sociales y naturales". Tres encuestados ubicaron a la historia ambiental tanto en las ciencias sociales como en las humanidades: un doctor en antropología mencionó que, como la antropología misma, la historia ambiental está "a veces en las humanidades y a veces en las ciencias sociales, con la necesidad de vivir con esta tensión", otro encuestado añadió "aunque la verdad no importa tanto donde se ubique sino cómo se hace". 


\section{LA H. A. Y LAS ÁREAS DEL SABER}

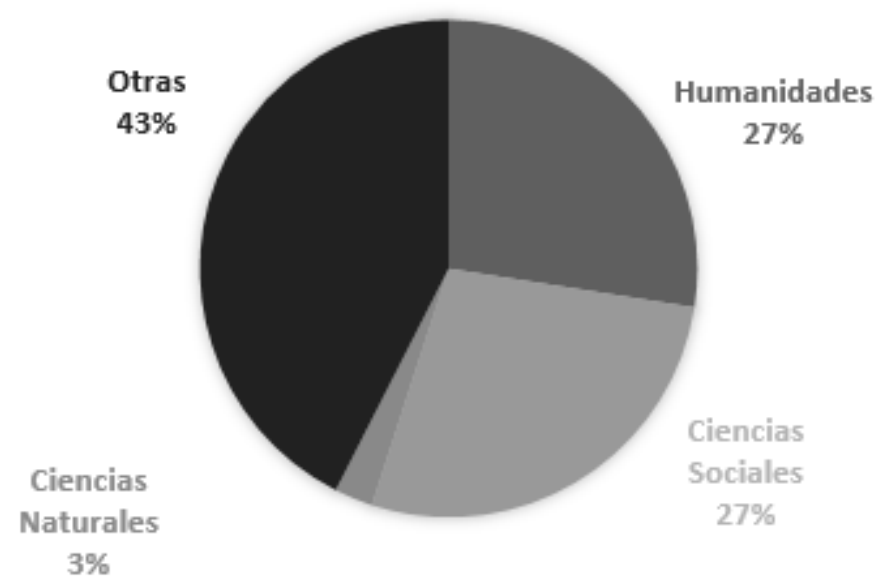

De modo que, en resumen, de entre los 17 encuestados que ubicaron a la historia ambiental en una relación con el conocimiento distinta a la triada del árbol del conocimiento moderno: siete plantearon que la historia ambiental es transdisciplinaria, interdisciplinaria, o multidisciplinaria. De estos siete, uno planteó que es una transdisciplina que intersecta con las humanidades, las ciencias sociales y las ciencias naturales, y otro planteó que es un campo inter-transdisciplinario entre ciencias sociales y ciencias naturales; por tal razón estos dos datos también son considerados en el conteo siguiente. Siete plantearon que la historia ambiental pertenece a todas las áreas del saber consideradas. Tres plantearon que la historia ambiental pertenece tanto a las humanidades como a las ciencias sociales. Dos plantearon que la historia ambiental pertenece tanto a las ciencias sociales como a las ciencias naturales: Mientras que sólo un académico planteó que es una disciplina compleja.

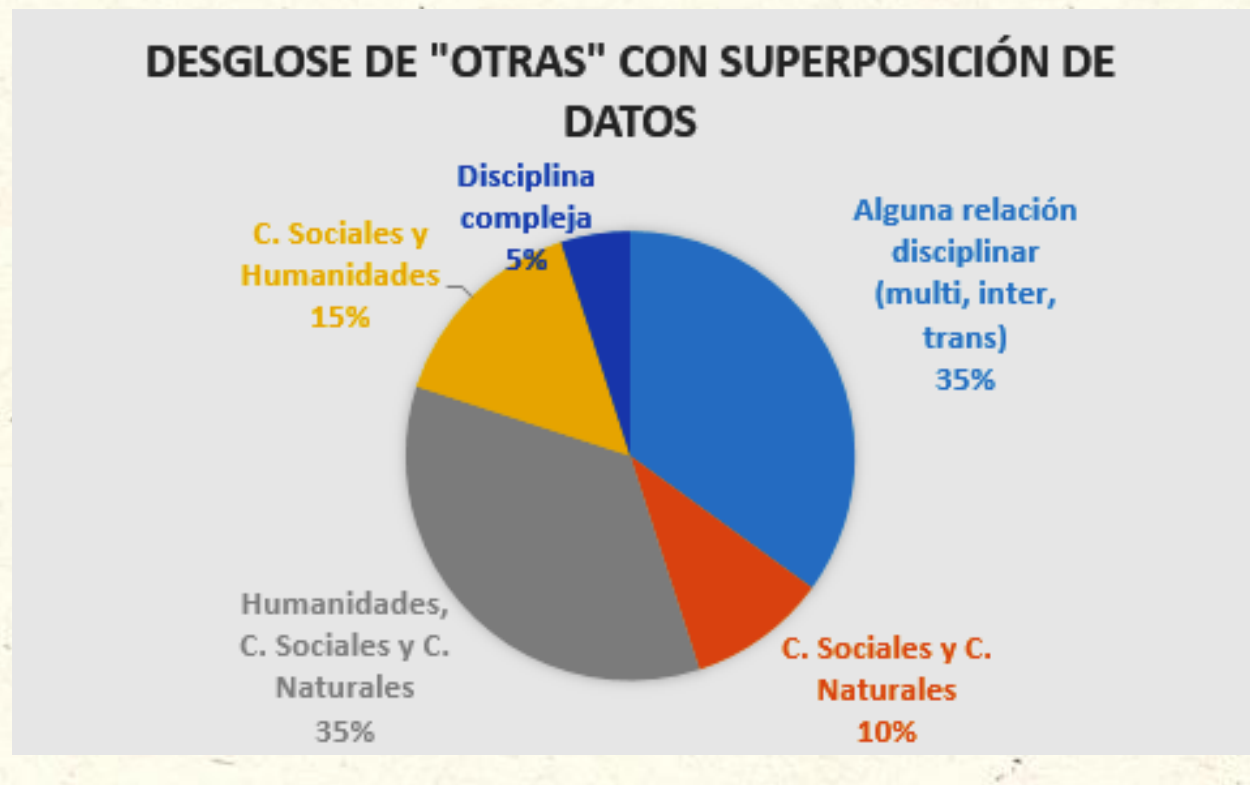

\section{¿Disciplina, interdisciplina 0 transdisciplina?}

Como la tercera pregunta requiere de un análisis no estadístico, se plasman primero los resultados de la cuarta pregunta, que buscó que el encuestado respondiera si considera que la historia ambiental es una disciplina, una interdisciplina 0 una transdisciplina y que justificara su respuesta. Pregunta al parecer pertinente porque en las respuestas a preguntas anteriores, ya habían surgido entre algunos de los encuestados. 


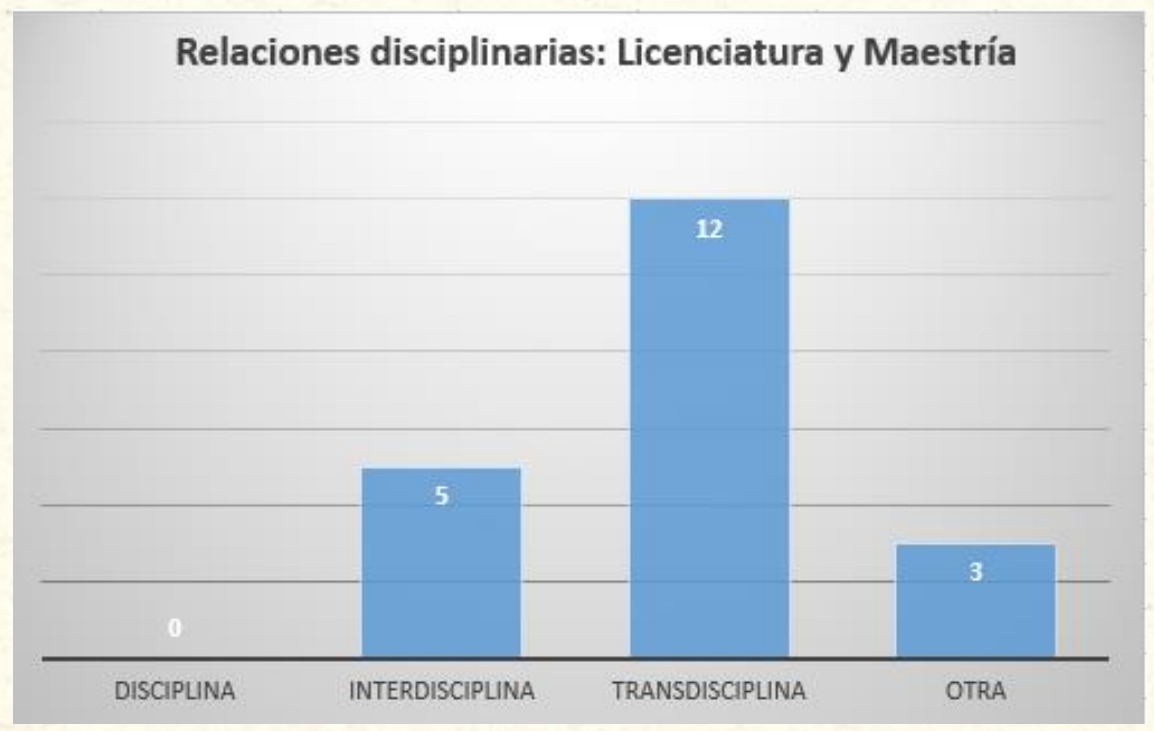

A trece de los encuestados less pareció que la historia ambiental es transdisciplinaria, doce la ubicaron como interdisciplinaria, cinco la plantearon como una disciplina, mientras que diez contemplaron otras opciones.

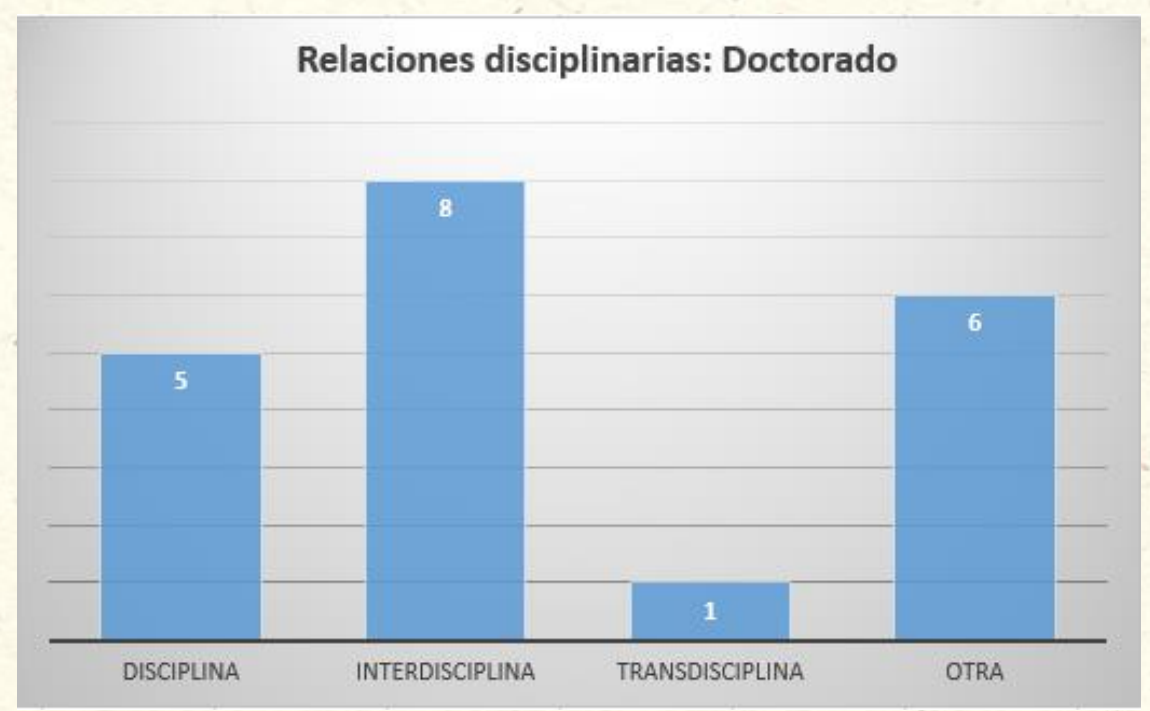

Entre estos diez, tres encuestados no escogieron ninguna de las opciones prediseñadas, pero tampoco plantearon su propia respuesta; de estos, uno indicó que no tenía como opinar, otro que no sabía si tenía sentido la diferencia y otro encuestado planteó que no era una pregunta pertinente, incluso mencionó que no sabía que era interdisciplina o transdisciplina a pesar de que en la segunda pregunta de la encuesta mencionó que la historia ambiental cabía en las humanidades, las ciencias sociales y en las ciencias naturales "porque es interdisciplinaria".

Hubo quien mencionó que la historia ambiental "es simplemente historia, sin embargo, con características interdisciplinarias por involucrar otras áreas del conocimiento", con lo que se sumará su respuesta a los que la postulan como interdisciplinaria. Dos personas plantearon que la historia ambiental es interdisciplinaria y transdisciplinaria, entre ellos María Eugenia Solari, quien añadió que "debe ser un campo inter-transdisciplinario que una ciencias sociales y naturales". Angela Bernardete Lima indicó que es un campo de estudios multidisciplinar. 


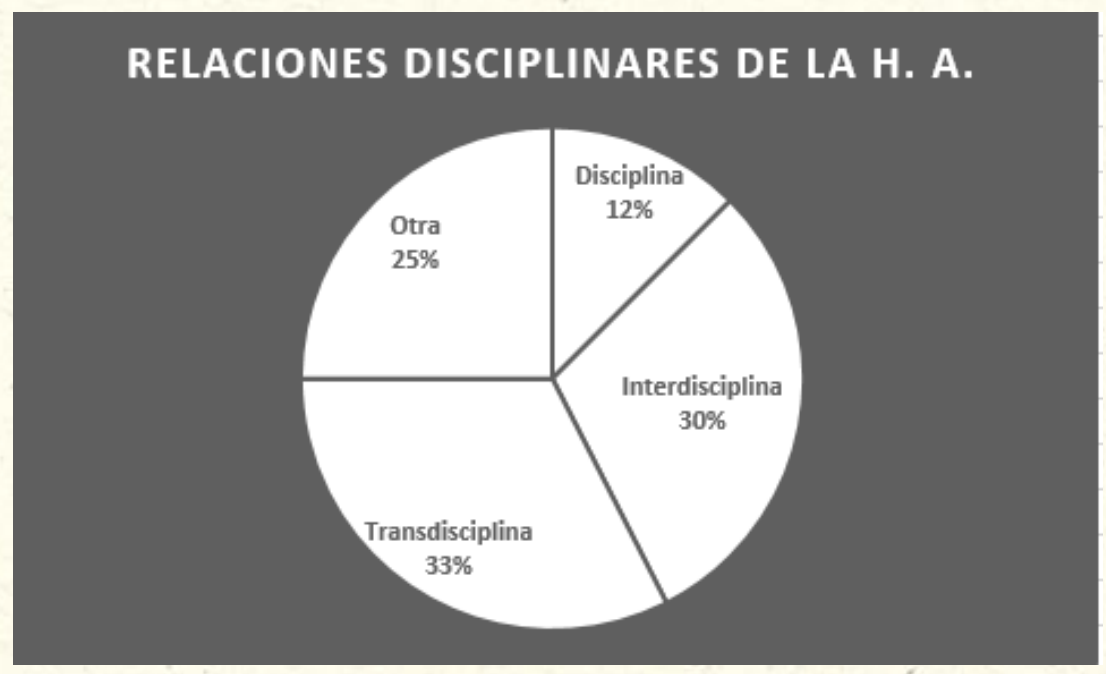

Hubo quien mencionó que la historia ambiental es un enfoque y un campo historiográfico, visión que de cierta manera compartieron Stuart McCook y Patricia Clare; el primero mencionó que la historia ambiental "es una subdisciplina de la historia" que a su vez está relacionada interdisciplinar/transdisciplinarmente tanto con otras ramas de la historia como con otras disciplinas académicas, la segunda indicó que "es una rama de la disciplina histórica" y añadió que "no es una transdisciplina porque los métodos debe ser pertinentes a la historia".

\section{DESGLOSE DE OTRAS.}

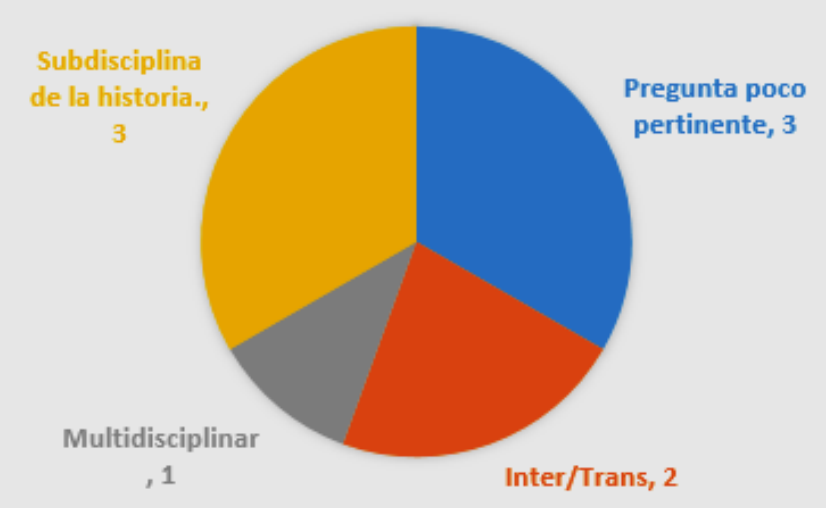

\section{Análisis cualitativo}

Antes de continuar con la tercera pregunta, se realizará el complemento de análisis cualitativo para las primeras dos preguntas, a través del cual y de forma complementaria, se añadirán otros análisis cuantitativos.

\section{Definición de ambiente y el lugar de la historia ambiental a las áreas del conocimiento}

La definición de Ambiente menos aceptada por los encuestados fue "el conjunto de características físicas, químicas y biológicas que tienen un lugar determinado". Esta definición comparte campos semánticos con "espacio", "arena", "entorno" y "medio" con lo que implica una posición epistemológica dualista, ya que el ser humano, a través de ella, posiciona al ambiente como afuera y opuesto a ellos. La definición de ambiente como "naturaleza socializada, es decir, naturaleza ya no tan natural, sino que domesticada; de cierto modo artificializada" se deriva de lo planteado por Clarence Glacken en Huellas en la playa de Rodas y David Arnold en La naturaleza 
como problema histórico.4 A pesar de que esta definición converge con los hallazgos de las investigaciones de la historia ambiental, es sumamente revelador que más encuestados hayan estado dispuestos a plantear otras definiciones, algunas diferencias y puntos en común tanto con esta definición, como con la siguiente, destacando las relaciones y articulaciones entre lo humano y lo no humano.

La definición que escogió el $72.5 \%$ de los encuestados se retomó de Enrique Leff, quien planteó que el ambiente es "la articulación no dualista entre sociedad y naturaleza". 5 Implícitamente, tal definición se opone a la definición dualista, pero para reforzar tal impresión se le añadió que tal articulación no sólo no es dualista, sino que también es compleja.

En toda su riqueza, el concepto de complejidad plantea interpretaciones de la realidad que remiten a autores como Humberto Maturana y Francisco Varela, Frijtof Capra, Heinz von Foerster, Edgar Morin y Gregory Bateson. El contacto con autores como los mencionados anteriormente permitiría a la historia ambiental "vincularse críticamente a las ciencias de la complejidad";6 con lo que se opone a la epistemología lineal mecanicista que es reduccionista y da base a las ciencias naturales, a las ciencias sociales, e incluso a las humanidades. Por esa razón, se planteó que el encuestado ubicara a la historia ambiental en alguna de estas, ya que de colocar a la historia ambiental sólo en alguna de ellas, el significado dado a ambiente por el $72.5 \%$ de los encuestados no podría ser pleno, sino que tendría aún herencias e inercias dualistas, que por el simple hecho de que en su mayoría no eligieron la definición dualista de ambiente, se nota una tendencia de parte de los historiadores ambientales a superar el dualismo.

Recordemos que el trívium y el cuadrivium medievales mutaron con la llustración y a través de la influencia de René Descartes, quien popularizó la separación dualista entre espíritu y materia que justificó la diferenciación entre las ciencias y las humanidades de la modernidad. Posteriormente, como una transformación de algunas humanidades, surgieron las ciencias sociales que imitaron a la física, considerada la principal de las ciencias naturales. De modo que las tres áreas o ramas del conocimiento se formaron y desarrollaron con bases dualistas. Además, la influencia del mecanicismo newtoniano alcanzó especialmente a las ciencias naturales y a las ciencias sociales, es decir, a las de mayor rigor de las tres. Por eso, es importante que entre las respuestas a la pregunta por la ubicación de la historia ambiental en las áreas del conocimiento, Gabriel Garnero mencionara que hay una discusión sobre "la validez de la división de la ciencia" en humanidades, ciencias sociales y ciencias naturales. En realidad tal división y tales categorías sólo tienen validez en una epistemología dualista.

Lo que implica que hay otras formas de comprender y organizar el conocimiento, como lo planteó Alejandro Martínez al inferir que hay otras categorías además de las "incluidas en esta pregunta". Entre estas, están las que lentamente van emergiendo de la hibridez implicada en la interdisciplinariedad y la transdisciplinariedad; así como de las emergentes ciencias ambientales (que son una de las posibilidades de concretar la tercera cultura de C. P. Snow), cuya práctica se vincula también a la complejidad y que no sólo está en la "intersección entre humanidades, ciencias sociales y ciencias naturales", sino que es "transversal" a éstas y las rearticula, es decir, las une superando la "tensión" que ahora podemos Ilamar dualista, que según el antropólogo encuestado tiene la antropología (ý por cierto, también la historia) de, a veces, considerarse "en las humanidades y a veces en las ciencias sociales".

No sólo 23 de los encuestados ubicó a la historia ambiental en sólo una rama del árbol del conocimiento dualista, a pesar de convivir en el VII SOLCHA con humanistas, científicos sociales y científicos naturales con interés en la historia ambiental desde "diferentes perspectivas", sino que les pasó desapercibido que si la historia ambiental estudia las relaciones entre las sociedades humanas y la naturaleza, tales relaciones no pueden leerse sólo a través de un área del conocimiento, sino que requieren del conocimiento, métodos y técnicas de lo humano/social y de lo natural.7 Esto implica que

De los 29 que plantearon la definición no dualista (sino compleja) del ambiente, sólo 13 (32.5\% de los encuestados) 8 escogieron la opción "otra" o plantearon que la historia ambiental se ubica en más de un área del

\footnotetext{
${ }^{4}$ Arnold David. La naturaleza como problema histórico. El medio, la cultura y la expansión de Europa, (México: Fondo de Cultura Económica, 2000) y Glacken, Clarence J. Huellas en la Playa de Rodas. Naturaleza y cultura en el pensamiento occidental desde la antigüedad hasta finales de/ siglo XIII (Barcelona: Ediciones del Serbal, 1996).

${ }^{5}$ Leff, Enrique. Aventuras de la epistemología ambiental: de la articulación de ciencias al diálogo de saberes, (México: Siglo XXI, 2006$): 27$.

${ }^{6}$ Morales Jasso, Gerardo. "Convergencias entre subdisciplinas historiográficas y la historia ambiental. Una aproximación teórica", Historia 2.0, 7 (2014): 32.

${ }^{7}$ Esto aplica también a Stuart McCook, María Cecilia Gallero y el antropólogo anónimo, quienes plantearon que la historia ambiental se ubica en el polo ciencias sociales/humanidades. Además, la afirmación de este párrafo puede compararse con la hecha por Worster, Donald, "Appendix: Doing Environmental History", Donald Worster (ed.), The Ends of the Earth: Perspective in modern Environmental History, (Cambridge: Cambridge University Press, 1988), 295.

${ }^{8}$ Entre ellos, Guillermo Castro H., María Cecilia Gallero, Stuart McCook, María Eugenia Solari, Alejandro Martínez, María del Consuelo Cuevas Cardona, Ricardo Moreira F. F., Ximena Carreras Doallo, Ángela Bernardete Lima y Lincon Broering Bruno.
} 
conocimiento. Lo que implica que se mantuvieron alejados del dualismo sólo $44.8 \%$ de los que habían escapado de éste al definir ambiente en la primera pregunta. Además, de entre estos, seis encuestados también escogieron la opción "otra" o plantearon que la historia ambiental se ubica en más de un área del conocimiento, con lo que dejan ver una transición entre una epistemología dualista a una epistemología compleja. Cuatrog de estos seis habían escogido otra definición de ambiente a las planteadas por la encuesta; y los dos10 restantes habían elegido "naturaleza socializada" como definición de ambiente, pero plantearon que la historia ambiental es interdisciplinaria con aportes de todas las áreas.

La tensión epistemológica que implica a la historia ambiental como un campo de investigación que trasciende la forma de conocimientos dualista es ejemplificada por la justificación de la respuesta de Guillermo Castro (para él, la historia ambiental se ubica en todas las áreas del conocimiento indicadas en la encuesta), quien a su vez, amplía la pregunta de la encuesta al preguntar "¿Qué ciencia no es natural? ¿Cuál no es una construcción social? ¿Existe una que no sea histórica?" y añadir que "La historia ambiental es-esta destinada a ser la historia general de la especie humana". Sin embargo, tal tensión también es ejemplificada por la inconsistencia en las respuestas que dio Katherinne Giselle Mora Pacheco a las preguntas uno y dos, pues mencionó que la historia ambiental relaciona ambiente y sociedad, pero también señaló que en la historia ambiental, "la sociedad es el asunto central"; Io que implicaría, así planteado, una definición de ambiente distinta a la de "articulación no dualista (sino compleja) entre sociedad y naturaleza", que es la que ella había escogido. En cambio, hubo consistencia en las respuestas uno y dos del encuestado que entendió que "el ambiente ha sido dominado (en parte), transformado u afectado por el hombre", pues había definido "ambiente" como "naturaleza socializada". Si bien esta respuesta no muestra una tensión epistemológica tan evidente, tal definición de ambiente puede ser planteada como una de transición entre una definición dualista que plantea el ambiente como lo externo al ser humano y una definición de ambiente que al integrar sociedad y naturaleza integra no a lo ambiental dentro de lo social, sino a lo social dentro de lo ambiental en un sentido sistémico, ya que un individuo es sistema y ambiente a la vez, ya que forma parte del ambiente de otros individuos, que a su vez forman parte del ambiente del primero. Se debe sumar a las dificultades anteriormente planteadas, el del concepto "medio ambiente", que tiene varios posibles significados: uno irónico (medio como mitad), uno reiterativo (medio como sinónimo de ambiente) y uno utilitarista (medio como recurso), probablemente, el último sentido sea el responsable de la continuidad del concepto medio ambiente y su apropiación por parte de los académicos.

\section{Historia ambiental: ¿disciplina, interdisciplina, transdisciplina o multidisciplina?}

Entre quienes plantearon que la historia es multi, inter, transdisciplinaria 0 interdisciplinaria/transdisciplinaria se cuentan 29 encuestados, mientras que 8 mostraron a la historia ambiental como una disciplina o una subdisciplina historiográfica y los tres restantes no escogieron ninguna de las opciones prediseñadas ni plantearon su propia respuesta.

Si bien, salta a la vista el cuestionamiento por la pertinencia de esta diferenciación o ubicación, también Ilama la atención que sea tan difícil caracterizarla sólo como 1) la que está Ilamada a ser " "la” historia” (como lo plantea Lourdes E. Lozano Centello) o la "historia general de la especie humana" (como lo plantea Guillermo Castro), 2) una subdisciplina de la historia, 3) una interdisciplina 0 4) una transdisciplinaria. Tal dificultad de caracterización incluso se muestra con la respuesta que da Patricia Clare a la pregunta cuatro de la encuesta al mencionar que la historia ambiental no es una transdisciplina sino que es una rama de la historia; pues en la página de la Sociedad Latinoamericana y Caribeña de Historia Ambiental se muestrà una entrevista en la que Clare menciona que la historia ambiental constituye un "trabajo transdisciplinar". 11

Si bien se puede criticar la caracterización como transdisciplinar o interdisciplinar de la historia ambiental, también se puede criticar su caracterización como disciplina o subdisciplina historiográfica, pues Gabriel Garnero, María Gabriela Torres, Carolina A. Luna y Fermín Ledezma Domínguez dan muestras de que no se puede entender a la historia ambiental sin las enseñanzas que adopta de disciplinas como la ecología y la antropología, y

\footnotetext{
${ }^{9}$ Ely Bergo de Carvalho, Carolina Ardila Luna, Daiana Campos y Fermín Ledezma Domínguez.

${ }^{10}$ Claudia Leal y Yuri Simonini.

${ }^{11}$ Clare, Patricia, "Mi experiencia con la historia ambiental: un camino de encuentros", Página web de la Sociedad Latinoamericana y Caribeña de Historia Ambiental, available on line.
} 
subdisciplinas como la geografía histórica. El cuarto menciona que la historia ambiental "está en construcción" y "se auxilia de otras disciplinas", la tercera que "hay muchas herramientas teóricas y metodológicas de diferentes disciplinas que construyen la mirada" de la historia ambiental, la segunda indicó que "el estudio de las interacciones entre las sociedades y la naturaleza requiere de análisis que van más allá de las disciplinas, es decir requiere un diálogo de saberes y entender la complejidad del mundo como unidad. Metodológicamente requiere de los métodos y técnicas de varias disciplinas". Por su parte, el primero observó en la historia ambiental "la generación de interpretaciones o relatos históricos que son complejizados mediante la incorporación de factores explicativos provenientes de disciplinas tradicionalmente poco miradas por los historiadores (dependiendo el caso de estudio es la biología, la geología, etc.). En aquellos casos en que el investigador que hace historia ambiental no es historiador, el caso es a la inversa, veo la incorporación de esquemas y la utilización de una "lógica histórica" en sus producciones." Para Garnero, lo que tienen en común "-+aquellos que hacen Historia Ambiental independièntemente de su procedencia es la proyección temporal de sus interpretaciones, cuya elaboración requiere estar familiarizado con el método de trabajo del historiador."

Stuart McCook logra sintetizar las posturas "2)", "3)" y "4)" al indicar que la historia ambiental "es una subdisciplina de la historia" que tiene relaciones interdisciplinar/transdisciplinarias con otras ramas de la historia y con otras disciplinas académicas. Pero, retomando la crítica de los tres académicos a esta pregunta, ¿tiene sentido tal diferenciación? En realidad no la tiene si se usan estas palabras indistintamente y si existe polisemia en estos términos. Y como actualmente estos conceptos oscilan entre la suma, diálogo, vinculación, complemento, unión, articulación, integración, fusión y síntesis de disciplinas; no se puede asegurar que para todos los encuestados el concepto de interdisciplina signifique que una disciplina se cruce e "involuc[re] otras áreas del conocimiento", así como sus modelos y teorías, y así construya su propio proceder metodológico. Faltaron elementos para entender qué significado daba el encuestado a cada uno de estos conceptos. Aunque, de cierto modo, las relaciones disciplinares, es decir las que van más allá de la disciplinariedad cualquiera sea su dirección, muestran que las perspectivas disciplinarias no bastan para abordar la realidad, sino que las disciplinas son marcos limitantes para hacerlo. De modo que se hace necesario recurrir a otras disciplinas y que la historia ambiental ingrese al debate entre ser multidisciplinaria, interdisciplinaria 0 transdisciplinaria, 12 en el entendido de que cualquier relación que se escoja, ya sea que se realice individualmente 0 en equipo, son todo un desafío para un disciplinado. Aunque, como no hay un acuerdo sobre qué signifiquen estos conceptos, cada investigador que los use, haría bien en definirlos.13 Si la definición de interdisciplinariedad implica una relación entre disciplinas que va más allá de la multidisciplina, pero que no pretende sustituirlas y la definición de transdisciplina implica una relación entre disciplinas que pretende sustituir las disciplinas de las que parte; entonces (sea pertinente 0 no), la postura de los autores de este artículo coincide con lo planteado en la encuesta por la historiadora de la biología María del Consuelo Cuevas Cardona para quien la historia ambiental "ahora es una interdisciplina, pero pronto se convertirá en una transdisciplina", idea que es convergente con la que plasma Isa Torrealba en "Sustentabilidad, historia ambiental y transdisciplinariedad".14

Resulte tener la historia ambiental tal devenir o no, habría que coincidir con la idea de María Cecilia Gallero sobre que "es muy difícil lograr la integración de ciencias humanas y "duras", pero es el mayor desafío que se impone a aquel que se aventura a realizar una investigación que se considere como de historia ambiental", después de todo, como lo planteó Guillermo Castro, la historia ambiental "es una disciplina en un marco cultural nuevo, aún emergente, organizado en torno al ambiente y lo ambiental como problema”. Por lo tanto, aún requiere que se debatan y mejoren sus fundamentos.

\section{Definición de historia ambiental y diferenciación para con la historia social}

La tercera pregunta consistió en que el encuestado diera su propia definición de historia ambiental y planteara qué la distingue de la historia social. Tuvo 39 respuestas y, en estas, no todos los encuestados plasmaron esta distinción, aunque en general los encuestados sí definieron a la historia ambiental. Para María

\footnotetext{
12 Morales Jasso, "Convergencias entre subdisciplinas", 32.

${ }^{13}$ Por ejemplo, véanse las distintas definiciones de multidisciplina, interdisciplina y transdisciplina en Interdisciplina Revista del Centro de Investigaciones Interdisciplinarias en Ciencias y Humanidades, $1(1)$.

${ }^{14}$ Torrealba, Isa. "Sustentabilidad, historia ambiental y transdisciplinariedad", Revista Sustentabilidades, 4 (2011).
} 
Eugenia Solari, ésta "debe dar cuenta de la historia de la relación entre la naturaleza humana y extrahumana" apoyada en el "consenso de la arqueología, historia, antropología y la relación con las ciencias naturales"; definición que coincide con la de Sofía de la Rosa Solano, pues plantea que ésta "estudia las mutuas relaciones entre sociedad y naturaleza en el tiempo", excepto que a diferencia de Solari que plantea que es una "disciplina", Solano plantea que es un "campo".15 Para María del Consuelo Cuevas Cardona, la historia ambiental "es el estudio del pasado de las relaciones ser humano-naturaleza que nos permiten comprender el por qué de la degradación y sus posibles soluciones"; mientras que Jackson A. Perez destaca que "la historia ambiental destaca a la naturaleza en los estudios históricos". La historia ambiental, para Jo Klanovicz "es aquella que utiliza el "ambiente" como categoría por la cual todos los elementos pueden ser leídos", especialmente "cuando se trata de la relación entre interacciones humanas y el pasado en términos de opciones sobre el uso de recursos". Eduardo Glavara indicó que "es un ejercicio de una narrativa histórica que contempla las relaciones humanas y la naturaleza" y Lourdes E. Lozano Centilla adujo que "la historia ambiental se remite al estudio de las formas de relacionamiento entre las diferentes culturas del pasado con la naturaleza". Podríamos sintetizar las definiciones anteriores de la historia ambiental como la "historia de las relaciones entre naturaleza y sociedad" humana, tal como lo que planteó un entrevistado anónimo.

A pesar de que se les pidió que distinguieran entre historia ambiental e historia social, nueve de los encuestados enfatizaron relaciones más armoniosas entre éstas.16 Hubo desde quien indicó que tal "es una distinción innecesaria porque la historia ambiental es transversal" (Laura Lorena Leguizmon) y quien expresó que "la historia ambiental y la social están íntimamente relacionadas", hasta quien indicó que la historia ambiental "puede ser también historia social y la social puede ser ambiental, siempre y cuando tome en cuenta la naturaleza como algo más que contexto o telón de fondo" (Claudia Leal); pasando por quien opinó que "la historia ambiental es parte de la social y viceversa" pues "las modificaciones e interacciones que una sociedad realiza sobre un territorio, crea influencias sobre éste" (Lincon Broering Bruno), quien no observó "una diferencia tan distante" entre estas, pues aunque "la ambiental enfatiza con mayor vigor que la social las relaciones entre naturaleza y sociedad", son "complementarias" (Ricardo Moreira F. F.), quien afirmó "no veo una separación entre ellas", excepto para antes de que el hombre existiera en la tierra, por lo que ambas historias "deben ser pensadas y exploradas conjuntamente". Así como por quien expresó que la historia ambiental está "ampliamente vinculada a la historia social" ya "Io económico" (Angela Bernardete Lima), quien consideró que "el punto de diferenciación que existe es que la Historia Ambiental intenta incorporar agentes no humanos en sus análisis", particularidad que "obliga al investigador a sumergirse en dinámicas con las que usualmente no está familiarizado y para ello recurre a marcos interpretativos, teorías, conceptos o directamente datos elaborados en otras disciplinas con las que la historia no ha dialogado tradicionalmente. Sin embargo, creo que encontrar una separación nítida entre ambas es tan dificultoso como encontrar los puntos de encuentro y de separación entre historia política, económica, social o cultural ya que ineludiblemente estas dinámicas están entrelazadas y deben ser adecuadamente sopesadas" (Gabriel Garnero) y quien mencionó que "depende del enfoque adoptado es posible crear relaciones [de la historia ambiental] con la historia social" (Yuri Simonini).

Cuatro encuestados se encuentran entre los nueve que intentaron armonizar historia social e historia ambiental y los diez que destacaron sus diferencias.17 Estos encuestados son Stuart McCook, Antonio José Alves de Oliveira y dos anónimos. Para el primero ambas están "interrelacionadas, pero son distintas, pues "la historia ambiental sí tiene una dimensión social", aunque "también tiene que ver con la historia intelectual/de las ideas, con la historia económica y la historia del paisaje". Mientras que el segundo expresa que "la historia ambiental comprende a la historia social" pero también incluye las dinámicas del mundo natural. Perspectiva que contrasta con la que postuló un encuestado anónimo que indicó que la historia social, que "aborda las relaciones sociales a lo largo del tiempo puede ser explorada por.diferentes perspectivas: género, ambiente, relaciones de poder", pero que "la historia ambiental forma parte de la historia social". A la que se suma la de otro anónimo, quien indicó que no sabía si la historia ambiental era "algo radicalmente distinto o sólo un enfoque "particular" de" la

\footnotetext{
${ }^{15}$ Campo es una metáfora de territorialidad y poder, bien sea de una profesión o disciplina. Mientras que disciplina es una metáfora que en su inicio hacía referencia a las carreras atléticas, de modo que hace referencia al entrenamiento/disciplinamiento y por lo tanto a la formación. Por lo que, aunque implican cosas distintas, están relacionadas.

${ }^{16}$ Quizá sea relevante mencionar que de estos nueve encuestados sólo tres ubicaron la historia ambiental en las ciencias sociales y los otros cinco, o bien, la colocaron en la opción "otra", o seleccionaron todas las opciones.

${ }^{17}$ De estos diez encuestados dos ubicaron a la historia ambiental en las ciencias sociales, dos en las humanidades, los otros seis escogieron más de una opción, todas las opciones, o bien, la opción "otra".
} 
historia social; Por lo tanto, ¿pertenece la historia ambiental a la historia social?, ¿sus estudios se traslapan? 0 ¿la historia ambiental absorberá a la historia social de forma transdisciplinar?

Se puedes responder de forma más completa estas preguntas al combinar varios puntos de vista. Mientras que la historia ambiental estudia la interacción del hombre en su "medio natural" en el tiempo. "En cambio, la historia social trabaja más sobre la sociedad en sí, el trabajo, aspectos económicos, migraciones, etcétera", (María Cecilia Gallero) así que la historia social "no contempla el paisaje y el medio ambiente" (Anónimo), de hecho, "muchas veces omite cuestiones ambientales" (Anónimo). Por lo tanto, "la historia ambiental se distingue de la historia social porque su objeto de estudio involucra dos elementos sociedad-naturaleza, que no se limitan al ámbito social y lo antropocéntrico" (María Gabriela Torres Montero). De modo que mientras la historia social "sólo ve las condiciones biofísicas como escenario o telón de fondo", de modo que presta atención "a la interacción humana" pero no presta tanta atención a la interacción que tienen "con los ecosistemas"; mientras que "la historia ambiental estudia las relaciones sociedad-naturaleza a través del tiempo" (Katherinne Giselle Mora Pacheco) "en todos sus ámbitos" (Daiana Campo González), relaciones que son "bidireccionales" (Carolina Ardila Luna) y "recíprocas", de modo que tienen "consecuencias a través del tiempo" (María Gabriela Torres Montero). Así que la historia ambiental enfatiza "la agencia de los no-humanos" (Carolina Ardila Luna), en cambio, "Io social en la historia" podría contemplar estos aspectos "pero no en profundidad, mientras la ambiental si busca tener líneas un poco más delineadas" al respecto (Daiana Campo González). Además, otra de las diferencias entre ambas se da "porque la historia ambiental considera a la naturaleza no como algo estático sino en su carácter dinámico e "influenciando" la trayectoria de las sociedades humanas con las cuales está relacionada en términos dialécticos" (Alejandro Martínez, científico natural).

Al confrontar ambas perspectivas podría ser confuso el lugar de la historia ambiental para con la historia social, 18 pero las separaciones que hacen Guillermo Castro y Ely Bergo de Carvalho podrían esclarecer la relación que tienen ambas. Para Castro, la historia ambiental es "el estudio de las interacciones entre los sistemas sociales y los sistemas naturales a lo largo del tiempo", mientras que la historia social "se limita a la formación/transformación de los sistemas sociales". Para Carvalho "lo que define a la historia social es el abordaje de [...] las conformaciones sociales", mientras que "la historia ambiental es un abordaje a partir de la emergencia de la complejidad ambiental.19 De modo que la referencia al sistema, da pie a una lectura sistémica y no dual de la realidad, teniendo en cuenta que sistema es un concepto que según Edgar Morin sólo "tiene sentido si es capaz de aprehender, al mismo tiempo, unidad y diversidad, continuidad y rupturas" 20 de modo que se dé un abordaje emergente sobre la complejidad ambiental, que implica una relación con el conocimiento distinta a la tradicional, de modo que mientras la historia social está en una tensión entre pertenecer a las humanidades y a las ciencias sociales, la historia ambiental se nutre de estas y de las ciencias naturales, así que si la historia ambiental busca hallar su nicho no lo hará en las humanidades, en las ciencias sociales ni en las ciencias naturales, podría ubicarse en las ciencias ambientales. Lo que implicaría un cambio epistemológico de fondo, pero que ya se entrevé en las respuestas de algunos encuestados, especialmente porque destacan el enfoque en lo relacional de la historia ambiental (Antonio Jose Alves de Oliveira y Laura Lorena Leguizamón).

Sin embargo, entre las respuestas a la encuesta también existen afirmaciones y definiciones que tienen implicaciones dualistas: Claudia Leal plantea que la historia ambiental estudia "las relaciones entre sociedades y pueblos y el medio ambiente", de modo que explícitamente separa sociedad y ambiente, como lo hace Patricia Clare, Fermín Ledezma Domínguez, Lincon Broering Bruno y Adrián Gustavo Zarilli. La primera, al mencionar que

\footnotetext{
${ }^{18}$ Algunas otras similitudes de la historia ambiental para con otras formas de hacer historia se destacan en Morales Jasso, "Convergencias entre", $15-36$.

${ }^{19}$ Este encuestado remite en su respuesta a la lectura de Carvalho, Ely Bergo de. "História ambiental: muitas dúvidas, poucas certezas e um desafio epistemológico", Semana de Iniciação Científica 2 (2002): 165-181 y a Leff, Enrique .Construindo a História Ambiental da América Latina", Esboços, 13 (2005): 11-30, disponible en http://www.periodicos.ufsc.br/index.php/esbocos/article/view/383/9913 y parcialmente disponible en español en Leff, Enrique. Saber ambiental. Sustentabilidad, racionalidad, complejidad, poder, (México: Siglo-XXI/PNUMA/Centro de Investigaciones Interdisciplinarias en Ciencias y Humanidades, 2002): $327-341$.

En el artículo de Carvalho, se deslinda a la subdisciplina de la historia ambiental del determinismo geográfico y se plantea a ésta no como un campo sino como una forma de aproximación que busca entender la interacción entre las "antroposociedades" y "el ambiente "natural"”. La historia ambiental se diferencia de la historia social porque mientras la social estudia las antroposociedades como si existieran a parte del ambiente, la ambiental estudia las interacciones reciprocas de las antroposociedades con la naturaleza no humana. El artículo de Leff deferencia a la historia ambiental de la historia ecológica, de la ecología humana y de la historia social, pues esta última se muestra como una historia desnaturalizada. También se plantea que la historia ambiental es un campo disciplinar que surge tras la construcción social del concepto de ambiente, tal disciplina da cuenta de la emergencia de la complejidad ambiental que problematiza las relaciones entre ecología y economía a partir del poder y de la cultura y por lo tanto, ayuda en la construcción de una nueva racionalidad ambiental que permita la construcción de la sustentabilidad. Como para Leff la historia ambiental da lugar al saber ambiental, establece un programa de investigación que consiste en cuatro vertientes privilegiadas de estudio (la historia epistemológica de la complejidad ambiental, la hermenéuticas de las narrativas sobre las relaciones sociedad-naturaleza, la complejización de los tiempos en la era de la sustentabilidad como solidaridad transgeneracional, y los actores sociales, los movimientos ambientales y la apertura de la historia a lo no humano).

${ }^{20}$ Morin, Edgar. Introducción al pensamiento complejo (Barcelona: Gedisa, 2007): 77
} 
"la historia ambiental se enfoca en las relaciones entre seres humanos en sociedad y los ambientes", el segundo considero que la historia ambiental "es la explicación histórica de la transformación del ambiente natural por la compleja intervención hombre-sociedad", el tercero llamó la atención sobre "las formaciones sociales y su interacción con el ambiente natural" y el cuarto encontró que la historia ambiental "es la relación compleja entre sociedad y ambiente en una perspectiva histórica". Por lo que a pesar de destacar la complejidad de la relación entre sociedad y ambiente, el concepto de ambiente que allí plantean dos de los cuatro autores antes mencionados no coincide con el de "articulación no dualista (sino compleja) entre sociedad y naturaleza", que es el que habían elegido. Esto no necesariamente quiere decir "razón cínica", en el sentido de Peter Sloterdijk y Slavoj Žižek, la cual implica que la persona "reconoce las equivocaciones de una perspectiva ideológica pero, no obstante, afirma 0 sigue sus postulados".21 Más probable es que se deba a inercias paradigmáticas relacionadas con una formación dualista, pues reentrenar el ojo es un reto para el historiador que deviene en historiador ambiental.

Un encuestado anónimo planteó que la historia ambiental es "el análisis temporal de la historia de la sociedad en el medio en el que se desarrolla" y en tanto que medio y ambiente comparten los campos semánticos ligados al dualismo como sinónimos, el significado de "medio ambiente" (Ximena Carreras) tampoco es consistente con la definición de ambiente como "articulación no dualista...". Otro encuestado indicó que lo que distingue a la historia ambiental de la social "es la preocupación por el ambiente natural", lo que implica también una definición de ambiente como un afuera espacial que justifica el uso de un significante que incluya a lo social, es decir, una definición de ambiente dual, tal es también el caso de la palabra "socioambiental", la cual, sin embargo, es al mismo tiempo una forma de encarar ese dualismo.22

Por lo tanto, ¿es el ambiente algo que está afuera de lo humano?, ¿es naturaleza socializada?, ¿es un concepto que articula lo que nunca debió estar escindido, es decir lo natural y lo social? Quizá la respuesta les pareció clara a los encuestados en sus primeras definiciones, pero luego en su uso concreto denotaron no sólo distintos significados al que habían escogido en un inicio, sino que incluso algunos eligieron significados que contradecían la definición que preferían. La encuesta aquí plasmada puede ser reproducida posteriormente. Si esto sucede y los historiadores son influidos por la reflexividad y el pensamiento crítico, las respuestas serían diferentes a las ahora obtenidas. De aún carecerse de esto, los resultados de una segunda encuesta serían similares a los actuales.

\section{Conclusión}

La etiquetas comodín se usan cuando no hay un dominio propio y los perfiles son borrosos, es decir cuando la disciplina es joven,23 que es lo que pasa cuando se usa "medioambiente" y "socioambiente". Pero el objetivo de evidenciar algunas de las contradicciones incurridas en las respuestas a estas preguntas no es destacar errores, sino que parafraseando lo que dijo Marcelo Pakman para la cibernética, mostrar que la historia ambiental es un tipo de saber cuyo "núcleo central" se basó en "trascender la distinción cartesiana". 24 Pero, aunque la historia ambiental se originó precisamente en la búsqueda por la superación del dualismo y el viraje a la complejidad, aún los académicos están luchando por alejarse de las inercias académicas dualistas. Así que no se deben leer las contradicciones como errores por parte de los encuestados, sino como tensiones epistemológicas que están presentes en el colectivo de pensamiento formado por historiadores ambientales, tensiones que aparecen porque "estilos [de pensamiento] diferentes tratan de interactuar sin dar cuenta de esta diferenciación", algo que incluso puede conllevar "bloqueos en el mutuo aprendizaje"; así que tales tensiones requieren de una resolución. Por lo tanto, una vez que la presentación de estas definiciones aumentó las alternativas de interpretación posibles para los participantes (incluyendo a los autores mismos), 25 la propuesta aquí presentada implica el fortalecimiento teórico que permita que exista consistencia en las definiciones utilizadas por los académicos de distintas

\footnotetext{
${ }^{21}$ Lacapra, Dominick. Historia en tránsito. Experiencia, identidad, teoría crítica (Buenos Aires: FCE, 2006) 292.

${ }^{22}$ Fuera de la encuesta, en un comentario realizado en una de las mesas del VI Simposio Solcha, Juan Pablo Iglesias Zúñiga mencionó que "la perspectiva históricoambiental critica la dualidad occidental naturaleza cultura".

${ }^{23}$ Serna, Justo y Anaclet Pons. La Historia cultural: autores, obras, lugares (Madrid: Akal, 2005): 91.

${ }^{24}$ Pakman, Marcelo. "Comentario introductorio", Las semillas de la cibernética. Obras escogidas. Edición de Marcelo Pakman. Presentación de Carlos Sluzki (Barcelona: Gedisa, 1991): 84.

${ }_{25}$ Pakman, "Comentario introductorio", 105, 106
} 
formaciones que investigan historia ambiental y los usos de ambiente; Io que requiere, de cierto modo, limitar los significados aplicables a ambiente e historia ambiental.

Si bien, se encontraron algunas inconsistencias entre los encuestados, como enseña Thomas Kuhn en La Estructura de las Revoluciones Científicas, no podemos desechar una teoría o ciencia sólo por encontrar incompletitudes e imperefcciones que no le permiten corresponderse con el estereotipo metodológico de la ciencia. Cada ciencia pasa por ajustes. Y eso es lo que está pasando con la historia ambiental, donde la transición entre paradigmas tampoco puede hacerse lentamente, forzada por la lógica.26 Estamos ante un conflicto de paradigmas, por eso existe una falta de consenso sobre el objeto de estudio, así como sobre la metodología que implica la construcción del objeto.27

Quizá los autores de este artículo aún no puedan ser considerados como historiadores ambientales, y es por eso que cobra relevancia cerrar con la sugerencia del anónimo doctor en antropología encuestado, quien expresó que no deben ser otros quienes digan lo que la historia ambiental es, sino que son los historiadores ambientales quienes deben definirse a sí mismos y a su campo de estudio, lo cual será posible a través de la cogeneración del lenguaje que se genere tras la reflexión en que cada una de las grandes líneas de las definiciones consideradas permiten y/0 restringen oportunidades de entendimiento.28 Por lo tanto, los resultados de esta encuesta multidisciplinaria (por las formaciones tanto de los encuestados como de los encuestadores) e interdisciplinaria (por la integración de herramientas historiográficas, estadísticas y epistemológicas) pretenden ser sólo unos apuntes que plantean distintas perspectivas por parte de diferentes académicos y asistentes al VII SOLCHA que permitan trascender "las limitaciones [del] propio mirar, a través de la mirada de los demás" en una "indagación mutua" de "las condiciones de nuestro conocer el mundo".29 De manera que sería útil complementar las reflexiones que surjan a partir de las respuestas obtenidas en esta pesquisa mediante algunos textos realizados por dos de los historiadores ambientales aquí encuestados: "História ambiental e 0 ensino de história: uma difícil aproximação" e "História ambiental: muitas dúvidas, poucas certezas e um desafio epistemológico" de Ely Bergo de Carvalho y "La historia ambiental y el fin de la utopía metafísica de la modernidad", del entrevistado Manuel González de Molina y de Víctor M. Toledo,30 ya que los tres textos abordan las implicaciones epistemológicas que tiene la historia ambiental. Además, la lectura de estos textos permite encontrar ausencias sustanciales en la Encyclopedia of World Environmental History, que a pesar de contar con entradas como "Environmental ethics" por Michal P. Nelson y "Environmental Philosophy por Peter Hay, carece de entradas para "complejidad", "mecanicismo" y "dualismo" (y/0 "cartesianismo"); las cuales podrían ayudar a los historiadores ambientales a desarrollar su trabajo con bases epistemológicas más sólidas.31 Por su parte, I. G. Simons sí incluye dualismo en el glosario de Global Environmental History, como "La idea de que hay dos clases fundamentales de cosas 0 categorías las cuales se oponen unas a las otras, como 'hombre' y 'naturaleza', o 'económico' y 'no económico'. 'Bueno' y 'malo' son también ejemplos" por lo que es una definición aún muy esquemática.32

De modo que los apuntes generados mediante esta encuesta pueden coadyuvar a que los historiadores ambientales desarrollen más textos reflexivos con el fin de que debatan las definiciones aquí plasmadas y autorreferencialmente33 definan lo que la historia ambiental es y a dónde se dirige, ya sea mediante de textos teóricos o mediante estudios de caso y mirándose para verse mirar34 realicen más aportaciones no sólo a la historiografía en general, sino también a las ciencias ambientales. Quizá un punto de partida será hacer un

\footnotetext{
${ }^{26}$ Datri, Edgardo y Gustavo Córdoba. "Epílogo", Introducción a la problemática epistemológica. Una perspectiva didáctica de las tensiones en la Filosofía de la Ciencia (Rosario: Homo Sapiens, 2004): 211, 212.

${ }^{27}$ Miguelez, Roberto. Epistemología de las ciencias sociales y humanas (México: UNAM, 1977): 38.

${ }^{28}$ Pakman, "Comentario introductorio", 106.

${ }^{29}$ Pakman, "Comentario introductorio", 84, 85, 86.

${ }^{30}$ Carvalho, "História ambiental: muitas dúvidas, poucas certezas e um desafio epistemológico"; y González de Molina, Manuel y Víctor M. Toledo. "La historia ambiental y el fin de la utopía metafísica de la modernidad", Metabolismos, naturaleza e historia. Hacia una teoría de las transformaciones socioecológicas (Barcelona: Icaria, 2011): 19-57. Sobre este último texto, véanse especialmente las páginas 43-45.

${ }^{31}$ Krench III, Shepard; John R. McNeil y Carolyn Merchant (eds.), Encyclopedia of World Environmental History (New York: Routledge, 2004).

${ }^{32}$ Simons, I. G., Global Environmental History (Chicago: The University of Chicago Press, 2008): 256-260.

${ }_{33}$ Morin, Introducción al pensamiento complejo, 64 y Pakman, Marcelo. "Introducción", Las semillas de la cibernética Obras escogidas Edición de Marcelo Pakman Presentación de Carlos Sluzki (Barcelona: Gedisa, 1991): 23, donde la autoreferenca es definida como una operación lógica que es considerada por el lenguaje y el pensamiento buscando la concientización. Miguelez, Martínez. El paradigma emergente. Hacia una nueva teoría de la racionalidad científica (Barcelona: Gedisa, 1993):130 indica que si después de que una persona realiza un negocio, esta persona se dice "me engañaron", es porque su mente analiza con posterioridad lo que antes sucedió, lo que sería un primer nivel de autorreferencia. Si después surge otro negocio y mientras está sucediendo esta persona piensa "me están engañando" es porque la mente de esta persona analiza el proceso actual y evalúa sus elementos; lo que sería un segundo nivel de autorreferencialidad. Si la persona menciona "iqué maravillosa es nuestra mente, que puede analizarse a sí misma y revisar críticamente sus propios procesos!" tenemos un tercer nivel de autorreferencia.

${ }^{34}$ Wagensberg, Jorge. Ideas sobre la complejidad del mundo (Barcelona, Tusquets, 1998): 117.
} 
Congreso 0 un seminàrio interinstitucional inspirado en el seminario de 1929 hecho por Lucién Febvre llamado Civilisation: le mot el l'idée que responda si usamos el mismo significado de ambiente sin vaguedad 0 contradicción, qué marco conceptual genera, forma parte este concepto y cómo resolver las diferencias que se detecten. 35

${ }^{35}$ Serna y Pons, La Historia cultural, 101 y Cunningham, William P. y Mary Ann Cunningham, "Understanding Our Environment", Principles of Environmental Science. Inquiry and Applications (New York: McGraw Hill, 2006): 11, 13. 